\title{
A new digital tool for radiographic bone level measurements in longitudinal studies

\author{
Hans R Preus ${ }^{1 *}$, Gerald Ruiner Torgersen², Odd Carsten Koldsland ${ }^{1}$, Bjørn Frode Hansen ${ }^{1}$, Anne Merete Aass ${ }^{1}$,
} Tore Arne Larheim ${ }^{2}$ and Leiv Sandvik ${ }^{1}$

\begin{abstract}
Background: The reproducibility of measurements on radiographs is influenced by the techniques by which the images as well as the measurements are obtained. Thus, bias resulting from errors in the image and/or image examinations at two points in time may result in wrongful registrations of true biological or pathological changes. The aim of the present study was to propose and evaluate an indirect radiological examination technique, by which bias, when measuring radiographic bone level, could be substantially reduced as compared to the technique using direct mm measurements.
\end{abstract}

Methods: A plugin to ImageJ was designed to reduce bias when measuring bone loss on radiographic images. In human dry mandibles, radiographic images of 20 teeth were obtained parallel with the tooth axis $(a l p h a=0)$ and at an angle of $30^{\circ}$ deviation. The direct technique of measuring radiographic bone level (RBL) and the indirect, length-adjusted RBL were registered by four researchers in a double blinded fashion.

Results: When mean RBL measured at $0^{\circ}$ angle was $7.0 \mathrm{~mm}$, the corresponding mean RBL measured at $30^{\circ}$ angle was $7.8 \mathrm{~mm}$, signifying an $11.4 \%$ increase $(p=0.032)$, whereas the mean length-adjusted RBL increased by $0.6 \%$ $(p=0.9)$.

Conclusions: This study showed that the use of the original, direct technique (ImageJ) resulted in markedly biased radiographic bone level at $30^{\circ}$ angle, while the proposed indirect length-adjusted technique (ImageJ plugin) did not.

\section{Background}

Periodontal destruction is most frequently described in $\mathrm{mm}$ periodontal pocket depth (PD) and clinical attachment level (CAL) [1-3]. However, despite being the most common way to convey periodontal disease, these soft-tissue measures are considered inaccurate, surrogate parameters reflecting an unpredictable combination of gingivitis and periodontitis as well as being variably affected by the examiners skill, reliability and technique [3-5].

Radiographic examination is an alternative to PD and CAL in evaluating periodontal bone level, and is considered a more reliable estimate of disease experience. A decrease or increase in the alveolar bone level at a given site over a period of time may be regarded as progression or

\footnotetext{
*Correspondence: hpreus@odont.uio.no

'Department of Periodontology, Institute of Clinical Odontology, Faculty of Dentistry, University of Oslo, PO 1109 Blindern0317 Oslo, Norway Full list of author information is available at the end of the article
}

regression of the disease process at that site [6]. However, registrations made on radiographs are influenced by the techniques by which the images, as well as the measurements, are obtained $[7,8]$. A long cone "paralleling technique" [9], with a standardized receptor holder [10], is recommended for obtaining the radiographs, and it has been suggested that the direct method (in $\mathrm{mm}$ ) should be used when investigating the susceptibility of different teeth to periodontal breakdown in clinical trials of comparative nature $[10,11]$.

However, researchers have warned that image distortions of the object (tooth) appear if there is deviation from the "paralleling technique" [12, 13]. This deviation is especially evident, as it is inevitable, in the upper jaw where the palatal anatomy prevents the ideal positioning of the receptor $[14,15]$. In a comprehensive study, Roeder and co-workers [16] reported mean angulation for central incisors and first molars to be $37^{\circ}$ (range 19-56 ) and $42.5^{\circ}$ (range $26-56^{\circ}$ ), respectively. Furthermore they 
showed "foreshortening" of the image of these teeth ranging from 5.4 to $44.1 \%$.

In longitudinal, clinical studies high reproducibility of registrations is of the essence, and distortion of imaged teeth and surrounding bone on radiographs will result in unreliable measurements of the bone level and tooth length $[17,18]$ and consequently, give a wrongful impression of loss or gain of bone over time. Researchers are therefore calling for new techniques that could correct such distortions [16].

The purpose of the present experimental study was therefore to propose and test a rapid and indirect, semiautomated radiographic method for periodontal bone level assessments that reduces the distortion of radiographic bone level (RBL) changes caused by varying angles when obtaining the radiographic image.

\section{Methods}

Seven human dry mandibles bearing 20 (already) loose teeth were used for this experiment. The use of these mandibles, for this experiment and under these conditions, did not require approval from the regional committee for research ethics due to national legislation. The physical lengths of each of the teeth measured by an electronic caliper (Cocraft', United Kingdom) are shown in Table 1. Mandibles were used in order to control the angle $(\boldsymbol{\alpha})$ between the receptor and the perpendicularto-the-central X-ray beam (Figs. 1, 2). None of the loose teeth and surrounding bone in these mandibles showed signs of severe periodontal disease as the mean distance from alveolar crest (AC) to the cemento-enamel junction (CEJ) was $1.7 \mathrm{~mm}$. "Severe" or "extensive" periodontitis is reflected by clinical attachment loss (CAL) of more than 5-7 mm [19, 20], which corresponds to a RBL of $>7 \mathrm{~mm}$. Since the dry mandibles did not display such degree of bone loss, an artificially reduced bone level was created by placing hard wax in the 20 sockets and replacing the teeth into the wax, allowing a stable marginal bone level of approximately $7 \mathrm{~mm}$ (Fig. 3a). One Eggen holder [10] was modified to give the $\mathrm{X}$ ray beam - receptor an angle $(\boldsymbol{\alpha})$ of $30^{\circ}$, mimicking a clinical situation [16] (Fig. 3b). A standard Eggen holder, with the receptor in a fixed parallel position with the tooth axis, was used as control $\left(\boldsymbol{\alpha}=0^{\circ}\right)$ (Fig. 3b). The experimental setup is shown in Fig. 3. Consecutive radiographs were obtained in each position $\left(\boldsymbol{\alpha}=0^{\circ}\right.$ and $\boldsymbol{\alpha}=30^{\circ}$ ), of the 20 teeth, by the same operator, scanned and stored. Individually fitted stents were used for securing identical placement of the holders during all exposures of the same area, also securing that the teeth did not sink further into the wax in the bottom of their sockets during the experiment. Radiographic images were obtained by the Soredex Digora Optime Digital imaging plate system film (Soredex, Finland) and a Planmeca intra (Planmeca Oy, Finland) X-ray unit. The images where exported by
Table 1 The physical length in $\mathrm{mm}$ of the 20 teeth with artificially elevated bone level as compared to the length obtained by reading the lengths on the radiographs

\begin{tabular}{|c|c|c|c|}
\hline Scull No. & Root designation & Root length in $\mathrm{mm}^{\mathrm{a}}$. & $\begin{array}{l}\text { Root length in } \mathrm{mm}^{\mathrm{b}} \\
\text { measured on } \mathrm{X} \text {-rays }\end{array}$ \\
\hline 1 & $36 M^{c}$ & 21.34 & 21.5 \\
\hline 1 & $36 D^{c}$ & 20.35 & 21.4. \\
\hline 1 & 35 & 20.71 & 21.6. \\
\hline 1 & 34 & 20.28 & 21,7 \\
\hline 1 & 32 & 23.36 & 23,4 \\
\hline 1 & 43 & 24.13 & 25.4 \\
\hline 1 & 44 & 21.20 & 21.3. \\
\hline 1 & 45 & 21.19 & 22.7 \\
\hline 5 & $37 \mathrm{M}$ & 20.14 & 20.4 \\
\hline 5 & $37 D$ & 19.13 & 19.5 \\
\hline 5 & 35 & 21.20 & 20.8 \\
\hline 5 & $47 \mathrm{M}$ & 20.23 & 22.6. \\
\hline 5 & $47 D$ & 19.52 & 20.7. \\
\hline 6 & 43 & 18.26 & 18.1. \\
\hline 6 & 44 & 18.90 & 19.5. \\
\hline 7 & $37 \mathrm{M}$ & 18.39 & 19.9. \\
\hline 7 & $37 D$ & 18.17 & 19.0. \\
\hline 7 & 35 & 20.10 & 20.4 \\
\hline 7 & 32 & 23.19 & 23.2 \\
\hline 7 & 42 & 23.75 & 24.3. \\
\hline 7 & 45 & 22.14 & 22.4 \\
\hline 8 & $47 \mathrm{M}$ & 19.06 & 19.8. \\
\hline 8 & 47D & 18.34 & 18.9. \\
\hline 9 & $36 \mathrm{M}$ & 21.19 & 21.4 \\
\hline 9 & $36 \mathrm{D}$ & 20.26 & 21.0 \\
\hline 10 & $33 \mathrm{M}$ & 18.98 & 19.7. \\
\hline
\end{tabular}

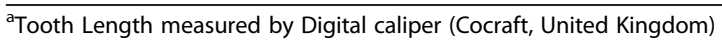
${ }^{\mathrm{b}}$ Average Tooth length measured on radiographs by examiner 1 (HRP) ${ }^{\mathrm{C}} M$ mesial root; $D$ distal root

the Digora for Windows software to 8 bit grey scale Tagged Image File Format (TIFF) files. The calibration information in the image files (i.e. Exif information) were used to obtain the coordinates of the sites. The files where then numbered, randomly reorganized and blinded to the readers.

The latest version of the ImageJ image processing and analysis software program [21] was used for the experiment (ImageJ http://rsbweb.nih.gov/ij/L. An application (plugin) to this program was designed (Fig. 4) with the intent to semi-automatically register the ratio between the bone level and the corresponding length of tooth (b/a, Fig. 5) (ImageJ plugin; http://www.odont. uio.no/english/research/projects/periodontal-diseases/). The original ImagJ processing and analysis software program 


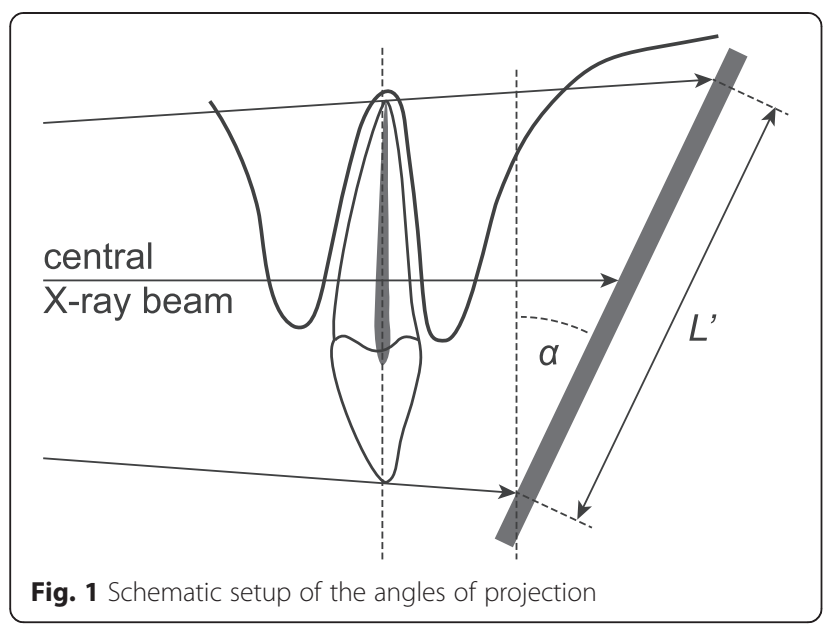

only allows for measuring absolute distances. The measured lengths of the teeth on radiographs are shown in Table 1.

On the digital radiographs points were registered (mouse-clicked) on the incisor edge/summit of crown (INC/OCL), the apex(es) of the root(s) (APEX), as well as the mesial and distal alveolar crests (AC) and cemento-enamel junctions (CEJ) (Fig. 4). For bicuspids and molars, the most elevated cusp on the image was registered, and the distance to the apex(es) was(were) registered from this one, most elevated cusp. The computer application automatically stored the marked coordinates (relative to the upper left corner of the image) and projected them onto an imaginary vertical axis parallel to the vertical dimension of the receptor. In the program the possibility to register restoration margins (RM, Fig. 5) was also designed, although being redundant in the present experiment. The coordinates, unit of length, time and date of measurement were automatically stored in a text file, which could be imported into any spreadsheet or statistical package to calculate length and all possible combinations of distances (Fig. 5) and ratios or percentages - thereof on the imaginary axis. In this study the ratios or percentages of the distance from the $\mathrm{CEJ}$ to the $\mathrm{AC}$ vs. the length of the tooth $(r e l \mathrm{RBL}=\mathrm{b} / \mathrm{a}$, Fig. 5) was the topic of interest.
The radiographs were read blindly twice, by four specialists in periodontology. The examiners were given a duplicate of two sets of digital radiographic images, obtained at $\boldsymbol{\alpha} 0^{\circ}$ and $30^{\circ}$. In one set of images the mesial and distal RBL (b, Fig. 5) were obtained by direct measurements using the traditional Image software program. In the other, the experimental ImageJ plugin was applied, and length adjusted RBL (relRBL) (b/a, Fig. 5) was obtained. In total, 40 sites on 20 radiographs obtained at each $\boldsymbol{\alpha}\left(0\right.$ and $\left.30^{\circ}\right)$ were read twice with both the direct (ImageJ) and indirect (ImageJ plugin) technique.

\section{Statistics}

When comparing mean score of data on a distance parameter, e.g., bone level, based on radiographs taken at $\boldsymbol{\alpha s} 0^{\circ}$ or $30^{\circ}$, a paired samples $t$-test was used, with $5 \%$ significance level. The statistical analysis was performed by using the statistical software program IBMSPSS version 18. The Intraclass Correlation Coefficient (ICC) [22] was used to estimate inter- and intraexaminer reliability for both the original (ImageJ) and new method (ImageJ plugin).

\section{Results}

The results from registrations of the radiographic images of tooth length, RBL, and length adjusted RBL (relRBL) (Fig. 5) are shown in Table 2. When mean RBL measured at $\boldsymbol{\alpha}=0^{\circ}$ was $7.0 \mathrm{~mm}$, the corresponding mean RBL measured at $\boldsymbol{\alpha}=30^{\circ}$ was $7.8 \mathrm{~mm}$. This $11,4 \%$ increase was statistically significant $(p=0.032)$. Table 2 also shows that the length of the tooth was significantly increased from one image to the next as the angle $(\boldsymbol{\alpha})$ increased from $0^{\circ}-30^{\circ}$ $(p<0.001)$.

We defined length-adjusted RBL (relRBL) as RBL divided by the length of the corresponding tooth $(\mathrm{L})$, which can be displayed as a ratio, or as a percentage of the tooth length. The mean length-adjusted RBL (relRBL) increased by only $0.6 \%$ (from 31.4 to $31.6 ; p=0.9$ ) when measured respectively at $0^{\circ}$ and $30^{\circ}$ angle.

The ICC for inter- and intra-examiner reliability of length of teeth $(\mathrm{L})$ measured by the direct and the indirect method were respectively 0.96 (95 \% Cl: 094$0.98)$ and $0.98 \quad(95 \% \quad \mathrm{Cl}: \quad 0.96-0.99)$. The

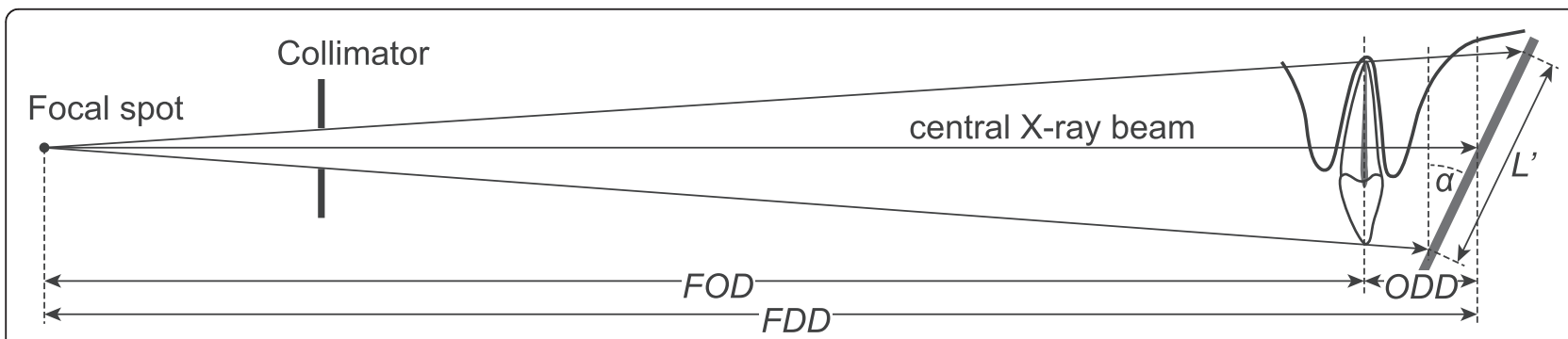

Fig. 2 Schematic setup of imaging geometry 


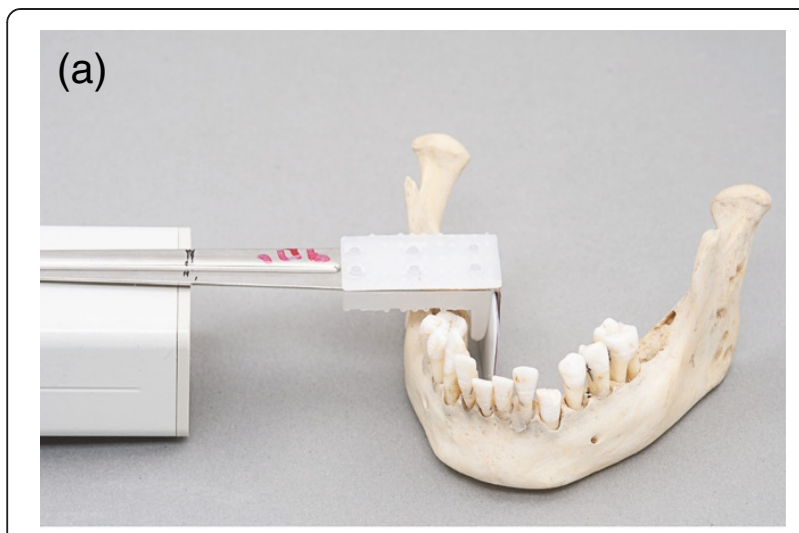

(b)

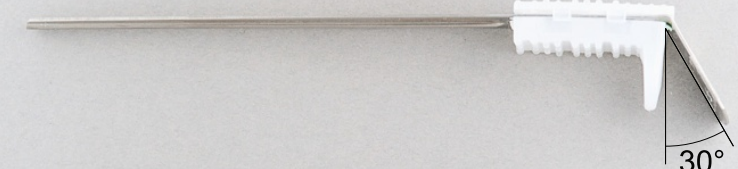

$30^{\circ}$

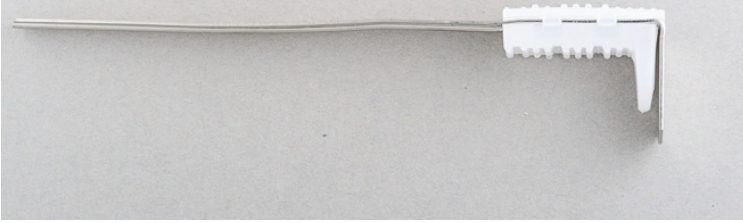

Fig. 3 a. Experimental setup showing elevated teeth in their sockets and Eggens holder with sensor at $a=0^{\circ}$. b. The Eggens holders with regular $a=0^{\circ}$ and modified to $a=30^{\circ}$ corresponding ICC for RBL were 0.86 (95\% Cl: $0.81-$ 0.89 ) and 0.94 (95\% Cl: 0.90-0.97) and length-adjusted RBL (relRBL) were 0.82 (95\% Cl: 0.75-0.88) and 0.94 (95 \% Cl: 0.90-0.97), respectively.

\section{Discussion}

The obvious distortion problem-especially with radiographs from the maxillary teeth [14]- its confirmation in clinical trials of comparative nature $[15,16]$, and the call for techniques that could correct for such distortions $[15,16]$, especially regarding an ongoing longitudinal clinical intervention study [23], prompted the development of the presented digital tool. It is clearly no more than a digital, more versatile version of the Schei ruler $[24,25]$ and Björn's technique [26, 27] that at present may be more useful in research, i.e., longitudinal studies where radiographic images are obtained more than once over several years. However, with the developing digital radiographic techniques, hard - and software, it might find its future usefulness to the clinicians as well.

The artificial bone levels, created by elevating the teeth in their sockets relative to the surrounding alveolar bone crest, did not differ from comparative in vivo bone levels of severe periodontal disease [19, 20]. Authentic dry skulls are hard to come by and even harder to use for studies due to considerations on ethics and preservation. Therefore, we could not find enough authentic dry mandibles with the desired amount of bone loss, and since removing bone to create an artificial bone loss of $7 \mathrm{~mm}$ was considered unethical, an artificial bone level was produced instead by elevating 20 teeth in their sockets. The choice of the angle $(\boldsymbol{\alpha})=30^{\circ}$ was made to mimic the

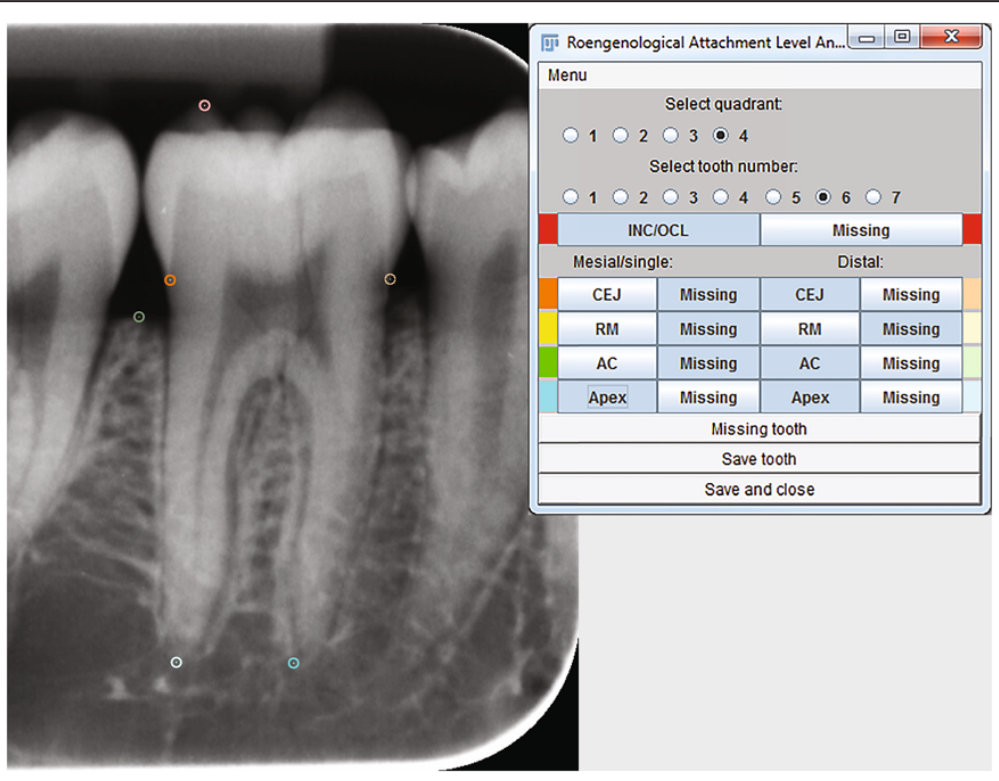

Fig. 4 Radiograph with markings and application (plugin) running 


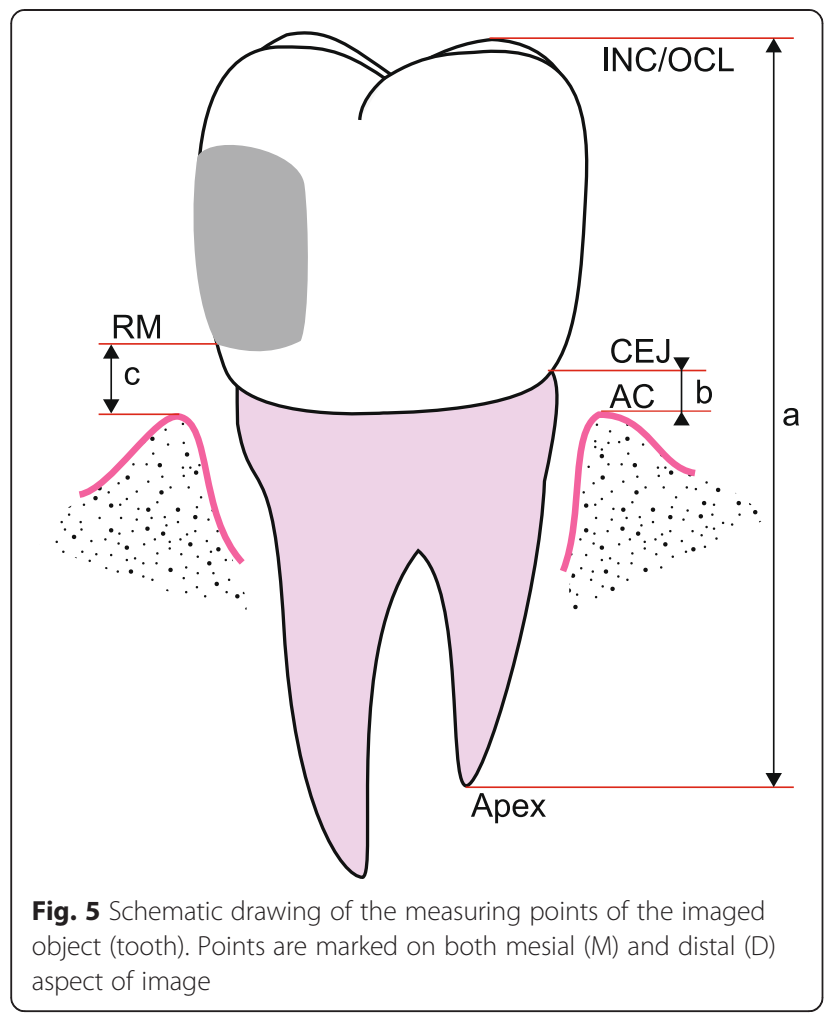

clinical situation [16] when obtaining radiographs; an angle that differ $30^{\circ}$ between the first and second exposure in a clinical situation is not uncommon. The bone level of $7 \mathrm{~mm}$ was chosen since severe [19] and extensive [20] periodontal diseases are described by CAL of $>5-7 \mathrm{~mm}$ corresponding to a marginal (AC-CEJ) and radiographic bone level $(\mathrm{RBL}) \geq 7 \mathrm{~mm}$.

Correlation to the true length of the teeth corresponded with the general notion that there is a 5-6\% magnification of a tooth projected onto a receptor during regular $x$-ray imaging (Table 1 ). The measurements were not corrected for this magnification since all images were obtained with the same personnel, technique

Table 2 Length of tooth = INC/OCL - APEX, RBL (Roentgenological Bone Level $=\mathrm{AC}-\mathrm{CEJ}$ ) and rel RBL (\%RBL/L) in $X$-rays obtained at 0 and $30^{\circ}$ angle with artificially increased $A L$ (actual bone level $\sim 7 \mathrm{~mm}$ )

\begin{tabular}{lllll}
\hline $\mathbf{a}$ & & 0 & $30^{\circ}$ & $p$-value \\
\hline INC/OCL - Apex (mm) & mean & 22.1 & 24.7 & $<0.001$ \\
& SD & 2.3 & 2.2 & \\
RBL (mm) & mean & 7.0 & 7.8 & 0.032 \\
& SD & 1.1 & 1.6 & \\
relRBL (\%) & Mean & 31.4 & 31.6 & 0.903 \\
& SD & 3.8 & 5.3 & \\
$\mathrm{~N}$ & & $N=40$ & $N=40$ & \\
\hline
\end{tabular}

and equipment. For obvious reasons, a new technique could not have been evaluated by measurements on regular in vivo radiographs since the actual bone level, length - and angles of the teeth in the jaw as well as the angle $(\alpha)$ would have been unknown values, not controlled by the researchers. Correlations to clinical measures were redundant in as much as the present study had to be ex-vivo since the aim was to evaluate the indirect radiological examination technique. However, a table has been added to show these values (Table 1).

A pre-study on 12 dry skull mandibles with 35 loose teeth was also performed before the bone level was artificially reduced in 20 of these teeth (described above) and produced practically the same results as those by Roeder et al. [15] (data not shown). However, in the present study, when the true RBL value was $7 \mathrm{~mm}$, as artificially achieved in these dry mandibles, this bias was significant and as large as $0.8 \mathrm{~mm}(>11,4 \%)$, whereas no significant bias was observed for the length-adjusted RBL (relRBL).

Considering that RBL and relRBL had similar intra and inter-examiner reliability, these results added to the notion that the indirect registration technique (relRBL) appeared to be a more reliable measure of bone loss than the direct registration technique (RBL). The use of the ICC may be controversial in clinical studies, and especially when the ICC coefficient is in the mid-ranges, since it is not easy to determine if a mid-range ICC score is good or bad. However, in this non-clinical study we deemed ICC as sufficient to examine inter - and intra examiners' reliability, especially since the ICC was mostly in the high - very high ranges.

There are clinical ways to reduce random or systematic errors during traditional radiographic examinations [28-31], and there are techniques to correct image distortion [13, 14, 32, 33], but these seem less suitable for large-scale, longitudinal studies that goes on for years. Another technique is anterior and molar/premolar bitewing radiographs. This technique may not be reproducible in patients with severe periodontal disease due to extensive bone destruction preventing the upper and lower jaw bone level to show on the same bite-wing image. Moreover, large receptors frequently cause patient convulsion and evasion reflexes that makes such images difficult to obtain. Thus, standardized peri-apical radiographs seem so far to be the method of choice to monitor bone level in longitudinal clinical interventions trials. However, this sets the stage for the aforementioned distortion errors.

The presented plugin technique finds general application as it may be used for other than periodontal measurements, like oral surgical, cariological and endodontic evaluations and purposes. However, the smaller the object or length measured, the less clinically significant is 
the distortion problem. Applying the attached formula (Fig. 1) it can be shown that if all objects or lengths measured in a study are below $2 \mathrm{~mm}$, the presented technique is of little value as compared to the direct technique. On the other hand, if all objects are larger than $2 \mathrm{~mm}$, or there is a variation in object size or length from below $2 \mathrm{~mm}$ and increasing, the presented technique has been found to be a useful and reliable tool. Moreover, it is still faster to use and less exhausting to the readers. Actually, with the above mentioned limitations, any radiographic measurement, over time, that diagnose changes in bone/tooth/tissue anatomy where the angle $\boldsymbol{\alpha}$ (Figs. 1, 2) may vary from examination to examination, may benefit from this technique. However, an adapted protocol/version (point definition) of the plugin should be produced for each purpose. This may be done by visiting the above mentioned website and downloading the plugin (ImageJ plugin; http://www.odont.uio.no/english/research/projects/periodontal-diseases/).

For obvious reasons, it was not possible to test convenience and rapidity of the new technique in a proper scientific manner. However, it should be mentioned that the presented technique seemed faster, and caused less exhaustion among the readers than the original technique. (These are personal observations, although all four readers subscribed to this statement).

\section{Conclusion}

When examining radiographic images for longitudinal changes of the periodontal bone level, the direct technique were markedly biased when the angle between the $\mathrm{X}$-ray beam and the sensor was $30^{\circ}$. This was not observed with the indirect, length-adjusted technique proposed in the present study. Thus the presented, indirect technique seems to be an appropriate radiographic method for longitudinal measurements of the periodontal bone level.

\section{Abbreviations}

AC: Alveolar crest; OCL: Summit of crown; CAL: Clinical attachment level; ODD: Object detector distance; CEJ: Cemento enamel junction; PD: Pocket depth; FOD: Focus object distance; relRBL: Length adjusted Radiographic Bone Level; FDD: Focus detector distance; ICC: Intraclass Correlation Coefficient; RBL: Radiographic bone level; INC: Incisor edge; RM: Restoration margin; L: Length of tooth; TIFF: Tagged image file format.

\section{Competing interests}

The authors declare no competing interests associated with this report.

\section{Authors' contributions}

HRP was the project leader, had the idea to - and wrote the specs for the plugin, obtained the radiographic images, served as blind reader and wrote the article. GRT wrote the plugin and adapted it to ImageJ, assisted in obtaining the X-rays and was responsible for blinding them to the readers, secured and unblinded data and communicated with the statistician (LS). $\mathrm{OCK}, \mathrm{BFH}$ and AMA were all blinded readers and participated in writing the manuscript. TAL was the radiological expertise, secured correct technique and participated in writing the manuscript. LS performed power calculations, statistics and participated in writing the manuscript. All authors read and approved the final manuscript.

\section{Acknowledgements}

This work was financed by the Norwegian Research Council, Oslo, Norway; grant \# 185120 and cont'd \# 229029. The plugin has been posted as shareware (public domain) in the UiO location http://www.odont.uio.no/ english/research/projects/periodontal-diseases/ Prof. Risnes, Institute for Oral Biology, Section of Anatomy and Physiology, Faculty of Dentistry; University of Oslo, Norway is thanked for providing the dry mandibles. Photographer F. Haugen Pedersen, Institute of Clinical Odontology, Section for Photography is thanked for photograpic work (Fig. 3).

\section{Author details}

${ }^{1}$ Department of Periodontology, Institute of Clinical Odontology, Faculty of Dentistry, University of Oslo, PO 1109 Blindern0317 Oslo, Norway.

${ }^{2}$ Department of Maxillofacial Radiology, Institute of Clinical Odontology,

Faculty of Dentistry, University of Oslo, PO 1109 Blindern0317 Oslo, Norway.

Received: 5 March 2015 Accepted: 2 September 2015

Published online: 08 September 2015

\section{References}

1. Haffajee AD, Socransky SS, Goodson JM. Periodontal disease activity. J Periodont Res. 1982;17:521-2.

2. Lindhe J, Haffajee AD, Socransky SS. Progression of periodontal disease in adult subjects in the absence of periodontal therapy. J Clin Periodontol. 1983;10:433-42.

3. Papapanaou PN, Lindhe J. Epidemiology of periodontal diseases. In: Lindhe J, Lang NP, Karring T, editors. Clinical Periodontology and Implant Dentistry, vol. I. Fifthth ed. Oxford: Blackwell Munksgaard; 2008. p. 130-79.

4. Salvi GE, Lindhe J, Lang NP. Examination of patients with periodontal disease. In: Lindhe J, Lang NP, Karring T, editors. Clinical Periodontology and Implant Dentistry, vol. I. Fifthth ed. Oxford: Blackwell Munksgaard; 2008. p. 573-86.

5. Larsen C, Barendregt DS, Slot DE, Van Der Velden U, Van Der Weijden F. Probing pressure, a highly undervalued unit of measure in periodontal probing: a systematic review on its effect on probing pocket depth. J Clin Periodontol. 2009;36:315-22.

6. Goodson JM, Tanner AC, Haffajee AD, Sornberger GC, Socransky SS. Patterns of progression and regression of advanced destructive periodontal disease. J Clin Periodontol. 1982;9:472-81.

7. Albandar JM, Abbas DK, Waerhaug M, Gjermo P. Comparison between standardized periapical and bitewing radiographs in assessing alveolar bone loss. Com Dent Oral Epidemiol. 1985;13:222-5.

8. Albander JM. Validity and reliability of alveolar bone level measurements made on dry skulls. J Clin Periodontol. 1989;16:575-9.

9. Updegrave WJ. The paralleling extension-cone technique in intraoral dental radiography. Oral Surg Oral Med Oral Pathol. 1951:4:1250-61.

10. Larheim TA, Eggen S. Measurements of alveolar bone height at tooth and implant abutments on intraoral radiographs. A comparison of reproducibility of Eggen technique utilized with and without a bite impression. J Clin Periodontol. 1982;9:184-92.

11. Albander JM, Abbas DK. Radiographic quantification of alveolar bone level changes. Comparison of 3 currently used methods. J Clin Periodontol. 1986;13:810-3

12. Van Aken J. Optimum conditions for intraoral roentgenograms. Oral Surg. 1969:27:475-91.

13. Schulze R, d'Hoedt B. Mathematical analysis of projection errors in "paralleling technique" with respect to implant geometry. Clin Oral Implants Res. 2001;12:364-71.

14. Schulze R, d'Hoedt B. A method to calculate angular disparities between object and receptor in "paralleling technique". Dentomaxillofac Radiol. 2002;31:32-8.

15. Roeder F, Brüllmann D, d'Hoedt B, Schulze R. Ex vivo radiographic tooth length measurements with the reference sphere method (RSM). Clin Oral Invest. 2010;14:645-51.

16. Roeder F, von Rechenberg I, d'Hoedt B, Schulze R. Spatial relation between a rigid (digital) intraoral $X$-ray receptor and longitudinal axes of maxillary teeth. Clin Oral Invest. 2011;15:715-9. 
17. Eikholz P, Hausmann E. Accuracy of radiographic assessment of interproximal bone loss in intrabony defects using linear measurements. Eur J Oral Sci. 2000;108:70-3.

18. Kim TS, Obst C, Zahaczek S, Geenen C. Detection of bone loss with different X-ray techniques in periodontal patients. J Periodontol. 2008;79:1141-9.

19. Page RC, Eke PI. Case definitions for use in population based surveillance of periodontitis. J Periodontol. 2007;78:1387-99.

20. Tonetti MS, Claffey N. Advances in the progression of periodontitis and proposal of definitions of a periodontitis case and disease progression for use in risk factor research. Group C consensus report of the $5^{\text {th }}$ European workshop in periodontology. J Clin Periodontol. 2005;32 suppl 6:210-3.

21. Rasband, WS. ImageJ, U.S. National Institutes of Health, Bethesda, Maryland, USA, http://imagej.nih.gov/ij/, 1997-2014.

22. Shrout PE, Fleiss FL. Intra-class correlations: Uses in assessing rater reliability. Psychol Bull. 1979;86:420-8.

23. Preus HR, Gunleiksrud T, Sandvik L, Gjermo P, Baelum V. A randomized, double blind clinical trial comparing four periodontitis teratment strategies. One-year clinical results. J Periodontol. 2013;84:1075-86.

24. Schei O, Waerhaug J, Løvdal A, Arno A. Alveolar bone loss as related to oral hygiene and age. J Periodontol. 1959;30:7-16.

25. Bassiouny MA, Grant AA. The accuracy of the Schei Ruler: A laboratory investigation. J Periodontol. 1975;46:748-52.

26. Björn $\mathrm{H}$, Halling $\mathrm{A}$, Thyberg $\mathrm{H}$. Radiographic assessment of marginal bone loss. Odont Rev. 1969;20:165-79.

27. Björn A-L, Björn H, Halling A. An abbreviated index for periodontal bone height. Odont Rev. 1975;26:225-30.

28. Benn DK. A review of the reliability of radiographic measurements in estimating alveolar bone changes. J Clin Periodontol. 1990;17:14-21.

29. Dubrez B, Jacot-Descombes S, Cimasoni G. Reliability of a paralleling instrument for dental radiographs. Oral Surg Oral Med Oral Pthol Oral Radiol Endod. 1995;80:358-64.

30. Zappa U, Simona C, Graf H, van Aken J. In vivo determination of radiographic projection errors produced by a novel filmholder and an x-ray beam manipulator. J Periodontol. 1991;62:674-83.

31. Wu JC, Huang JN, Zhao SF, Xu XJ, Zhang JC, Xia B, et al. Use of a simple intraoral instrument to standardize film alignment and improve image reproducibility. Oral Surg Oral Med Oral Pathol Oral Radiol Endod. 2005;100:99-104.

32. Schulze R, Bruellmann DD, Roeder F, d'Hoedt B. Determination of projection geometry from quantitative assessment of the distortion of spherical references in single-view projection radiography. Med Phys. 2004;31:2849-54.

33. Schulze RKW. Pose determination of a cylindrical (dental) implant in threedimensional radiograph. Dentomaxillofac Radiol. 2010;39:33-41.

\section{Submit your next manuscript to BioMed Central and take full advantage of:}

- Convenient online submission

- Thorough peer review

- No space constraints or color figure charges

- Immediate publication on acceptance

- Inclusion in PubMed, CAS, Scopus and Google Scholar

- Research which is freely available for redistribution 